\title{
Transport processes of the legume symbiosome membrane
}

\section{Victoria C. Clarke ${ }^{1}$, Patrick C. Loughlin ${ }^{1}$, David A. Day ${ }^{2}$ and Penelope M. C. Smith ${ }^{1 *}$}

${ }^{1}$ School of Biological Sciences, University of Sydney, Sydney, NSW, Australia

${ }^{2}$ School of Biological Sciences, Flinders University, Adelaide, SA, Australia

\section{Edited by:}

Daniel Wipf, University of

Burgundy, France

Reviewed by:

Yi Ma, University of Connecticut, USA

Daniel Roberts, The University of Tennessee, USA

Frantisek Baluska, University of

Bonn, Germany

\section{*Correspondence:}

Penelope M. C. Smith, School of Biological Sciences, University of Sydney, Macleay Building A12,

Science Road, Sydney, NSW 2006

Australia

e-mail: penny.smith@sydney.edu.au
The symbiosome membrane (SM) is a physical barrier between the host plant and nitrogenfixing bacteria in the legume:rhizobia symbiosis, and represents a regulated interface for the movement of solutes between the symbionts that is under plant control. The primary nutrient exchange across the SM is the transport of a carbon energy source from plant to bacteroid in exchange for fixed nitrogen. At a biochemical level two channels have been implicated in movement of fixed nitrogen across the SM and a uniporter that transports monovalent dicarboxylate ions has been characterized that would transport fixed carbon. The aquaporin NOD26 may provide a channel for ammonia, but the genes encoding the other transporters have not been identified. Transport of several other solutes, including calcium and potassium, have been demonstrated in isolated symbiosomes, and genes encoding transport systems for the movement of iron, nitrate, sulfate, and zinc in nodules have been identified. However, definitively matching transport activities with these genes has proved difficult and many further transport processes are expected on the SM to facilitate the movement of nutrients between the symbionts. Recently, work detailing the $\mathrm{SM}$ proteome in soybean has been completed, contributing significantly to the database of known SM proteins. This represents a valuable resource for the identification of transporter protein candidates, some of which may correspond to transport processes previously described, or to novel transport systems in the symbiosis. Putative transporters identified from the proteome include homologs of transporters of sulfate, calcium, peptides, and various metal ions. Here we review current knowledge of transport processes of the SM and discuss the requirements for additional transport routes of other nutrients exchanged in the symbiosis, with a focus on transport systems identified through the soybean SM proteome.

Keywords: legume, rhizobia, symbiosis, transport, membrane

\section{INTRODUCTION}

Nitrogen is an essential macronutrient for plants and can be a limiting factor in crop growth. Nitrogen fertilizer is often used to supplement soils and produce high quality yields, but production of commercial quantities of nitrogen fertilizer is energy-expensive and the fertilizer can have negative effects on the environment, causing pollution of ground water (Vance, 2001). A natural alternative to commercial fertilizers is symbiotic nitrogen fixation in legumes, which can reduce the need for nitrogen fertilizer and can boost nitrogen reserves in the soil.

Biological nitrogen fixation (BNF) by rhizobia in legume nodules is responsible for the addition of approximately 40 million tons of nitrogen to agricultural systems each year (Herridge et al., 2008). As well as providing a protein-rich food source for humans and animals, legume crops are used to enrich soil nitrogen reserves, enabling growth of other crop species (Oldroyd et al., 2011). BNF also has the added advantage of decreased environmental impacts compared to synthetic nitrogen fertilizers, and subsequent reduction in costs associated with crop production (Udvardi and Poole, 2013).
Due to its importance, the legume:rhizobia symbiosis has been the focus of much research, with the ultimate aim to improve existing symbioses and potentially expand BNF into other non-legume crop species, such as cereals (Beatty and Good, 2011).

\section{BIOLOGICAL NITROGEN FIXATION}

Biological nitrogen fixation occurs through activity of the enzyme nitrogenase, which is found only in certain prokaryotes, including those of the Rhizobiaceae family (or rhizobia). The enzyme converts atmospheric nitrogen to ammonium, a plant-available form of nitrogen, but requires large amounts of ATP to fuel the conversion (Halbleib and Ludden, 2000). Legumes, such as soybeans, are able to form an association with nitrogen-fixing soil bacteria of the Rhizobiaceae family (termed rhizobia). In this symbiotic relationship, atmospheric nitrogen is fixed by the bacteria and made available to the plant in exchange for organic acids and other nutrients (Lodwig and Poole, 2003). This mutually beneficial association occurs within specialized root structures termed nodules. 


\section{ROOT NODULE FORMATION}

The relationship between rhizobia and their legume hosts begins with the exchange of signals between the symbionts. Free-living rhizobia are attracted to legume roots through the exudation of phenolic flavonoid compounds (Hirsch, 1992). Flavonoid perception by rhizobia triggers the synthesis of Nod factors, symbiosisspecific lipochitooligosaccharide compounds which activate nodule organogenesis and induce cellular changes in the plant roots to facilitate bacterial infection (Oldroyd and Downie, 2004). The recognition of Nod factors leads to a series of morphological changes in receptive plant root cells including root hair deformation and the initiation of the infection thread through which the rhizobia travel into the root cortical cells. In the Medicago truncatula:Sinorhizobium meliloti symbiosis, two flotillins (lipid raft markers) are essential for infection thread initiation, suggesting this initiation process involves lipid rafts on the root cell plasma membrane. Infection results in polarized root-hair tip growth, invagination of the plant cell membrane and the formation of the nodule meristem (Timmers et al., 1999; Esseling et al., 2003). The formation of the nodule meristem in legumes can give rise to two distinct patterns of nodule development, determinate and indeterminate growth. Indeterminate nodules are characterized by a tip-growing meristem as opposed to the transient meristem present in determinate nodules (Oldroyd et al., 2011).

Once inside the cortical cells, the rhizobia divide and multiply, and these cells are now termed infected cells. As the infected cells expand inside the growing nodule, the rhizobia are released from the infection thread into vesicles termed symbiosomes (Roth et al., 1988). This was initially thought to be an endocytotic process, and indeed, the endosomal marker Rab7 is present on mature symbiosomes (Limpens et al., 2009). More recent studies, however, have demonstrated that exocytotic vesicle-associated membrane proteins are required during the formation of the symbiosis, suggesting rhizobial release into symbiosomes is an exocytotic process (Ivanov et al., 2012).

The symbiosome is surrounded by a membrane of plant origin known as the symbiosome membrane (SM) which is derived from the infected cell plasma membrane, but becomes specialized in its role to contain the rhizobia (Whitehead and Day, 1997). Within the symbiosome in determinate nodules, rhizobia continue to multiply before differentiating into bacteroids, the symbiotic form of rhizobia in which symbiosis-related genes are induced (Whitehead and Day, 1997). Mature symbiosomes result from the coordinated division of bacteria and growth of the surrounding SM.

\section{THE SYMBIOSOME MEMBRANE}

The SM surrounds one or more differentiated bacteroids, effectively excluding them from the plant cytosol. The region between the SM and the bacteroids is termed the symbiosome space (SS). The SM is a selectively permeable physical barrier between plant and bacteroid, representing a regulation point under plant control for the movement of solutes between symbionts. The SM is therefore proposed to contain an array of transporters and channels to facilitate this (Whitehead and Day, 1997).
After its initial formation, the SM undergoes enormous proliferation to enable it to accommodate the dividing bacteroids (Roth and Stacey, 1989). It is estimated that the SM surface area in an infected cell is up to one hundred times that of the plasma membrane (Roth and Stacey, 1989). Protein trafficking and secretion have important roles in the symbiosis, as the expanding SM requires the synthesis of large amounts of lipids and proteins to meet the increasing requirements for SM in the infected cell. The SM composition varies throughout the existence of the symbiosome to facilitate the different transport requirements of the symbionts (Whitehead and Day, 1997).

Several proteins have been identified which possess an Nterminal signal sequence directing them to the symbiosome (Liu et al., 2006; Hohnjec et al., 2009; Meckfessel et al., 2012). For example, the SS localized N-terminal region of $M$. truncatula nodulin 25 (MtNOD25) contains a signal peptide that can drive symbiosome targeting of heterologously expressed proteins, and this signal sequence is conserved across several other symbiosome proteins (Hohnjec et al., 2009). MtENOD8, a SS localized protein (Coque et al., 2008), also contains a signal peptide which directs subcellular targeting (Meckfessel et al., 2012) but it also contains an internal sequence directing it into the symbiosome, without the requirement for the $\mathrm{N}$-terminal signal peptide (Meckfessel et al., 2012). However, an N-terminal signal sequence is not present in all proteins targeted to the symbiosome, suggesting additional trafficking pathways exist (Catalano et al., 2004).

\section{IDENTIFYING SYMBIOSOME MEMBRANE TRANSPORTERS}

Analysis of rhizobia mutants for transport processes and their $\mathrm{N}$-fixation phenotype has been a useful method to identify the compounds transported across the SM (Udvardi and Day, 1997; Udvardi and Poole, 2013). SM transport proteins in soybean, M. truncatula, Lotus japonicus and other legumes have been identified using a range of biochemical and molecular approaches. M. truncatula forms indeterminate nodules, while soybean and L. japonicus both form determinate nodules. As well as differences in nodule meristem development, each species has distinct advantages for particular applications. Both $L$. japonicus and $M$. truncatula have small diploid genomes and a short life cycle well suited to genetic analysis. While soybean has a larger, polyploid genome, its larger and more numerous nodules allow easier extraction and isolation of symbiosomes and their components. Soybean is an agriculturally important legume and its genome has been fully sequenced (Schmutz et al., 2010).

The publication of the soybean genome, together with advance in sequencing technologies have enabled high-resolution transcriptome studies to be undertaken. Two soybean transcriptome atlases have been produced, detailing gene expression profiles in different soybean tissues including roots and nodules (Libault et al., 2010; Severin et al., 2010) and gene expression atlases are available for L. japonicus (Verdier et al., 2013) and M. truncatula (Benedito et al., 2008). These transcriptome databases provide a comprehensive resource for the identification of tissue-specific gene expression.

Recently, the combination of resources in soybean, together with the relative ease of SM protein extraction, has allowed the 
generation of a proteome of the soybean SM from Bradyrhizobium japonicum infected plants (Clarke et al., unpublished). This provides a rich resource of novel candidate SM transport proteins and here we discuss our current understanding of the transport processes of the SM as well as the potential roles for these recently identified proteins in the symbiosis.

\section{TRANSPORT ACROSS THE SYMBIOSOME MEMBRANE}

The SM is an interface that regulates the distribution of metabolites between the host plant and nitrogen-fixing bacteroids. The presence of transporters and channels on this membrane, whose activity and specificity can be tightly regulated, allows for the controlled distribution of metabolites and signaling molecules. Early work using biochemical assays with isolated symbiosomes provided the groundwork on which molecular and genomic research has expanded, although genes encoding many of these transport processes have not yet been identified (Figure 1; Table 1).

\section{TRANSPORT OF REDUCED CARBON}

The primary nutrient exchange across the SM is the transport of a carbon energy source from plant to bacteroid in exchange for fixed nitrogen. BNF is an energy expensive process which requires large amounts of ATP to fuel the reduction of $\mathrm{N}_{2}$ (Halbleib and Ludden, 2000). The host plant provides this from photosynthetic products that are oxidized in the bacteroids to generate ATP. This carbon source is derived from sucrose that is transported from source leaves through the phloem to the nodules (Udvardi and Day, 1997). Dicarboxylates are then transported across the SM to the bacteroids (Day et al., 1995). Assays with isolated soybean symbiosomes identified a carrier for monovalent dicarboxylate ions that had a higher affinity for malate than for succinate,

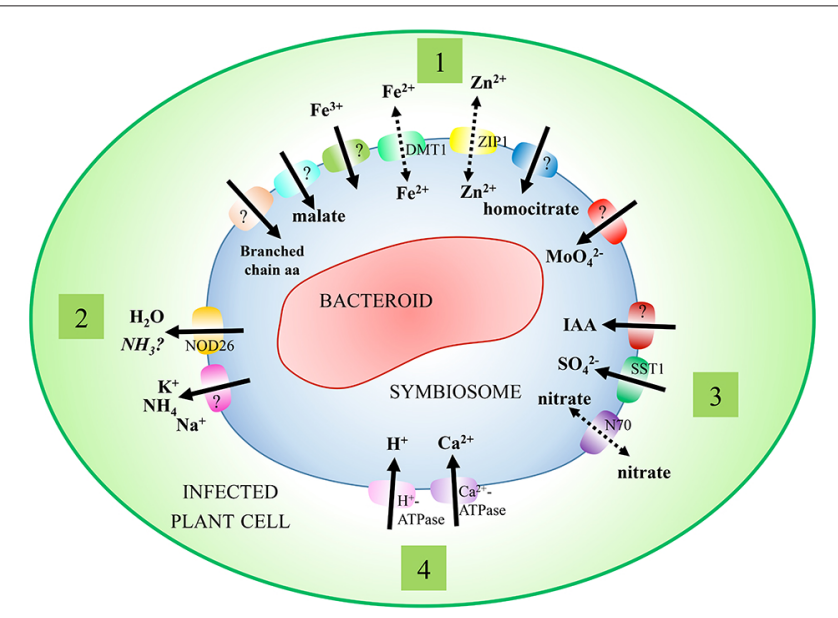

FIGURE 1 | Characterized transport processes of the symbiosome membrane. Symbiosomes exist within infected plant cells, where they act to partition nitrogen-fixing bacteroids from the cell cytosol. A range of transport processes have been characterized on the symbiosome membrane to facilitate movement of solutes between symbionts. These include (1) transport processes supporting the primary needs of symbionts (nitrogen, malate, and metal ions), (2) efflux processes (nitrogen), (3) secondary transport processes (nitrate, sulfate, and IAA), and (4) regulatory transport processes $\left(\mathrm{H}^{+}\right.$-ATPase, calcium, and water flux). suggesting that malate is the major form transported. The existence of this carrier was first demonstrated in soybean in 1988 (Udvardi et al., 1988; Udvardi and Day, 1997), but the protein that transports dicarboxylates has yet to be identified on the SM of any legume.

In the symbiosis-forming non-legume Alnus glutinosa, the AtNPF6.3 homolog, AgDCAT1, was identified and shown to transport dicarboxylates when expressed in E. coli, although its closest homologs have been characterized as nitrate transporters (Jeong et al., 2004). DCAT1 is a member of the nitrate transporter/peptide transporter (NRT/PTR) family (NPF; Léran et al., 2014). Members of this family are candidates for the dicarboxylate transporter in legumes as transcriptome data from a number of legume species has indicated that NPF encoding genes are induced strongly in nodules (Colebatch et al., 2004; Benedito et al., 2010; Libault et al., 2010; Severin et al., 2010). A number of members of the family were also identified in the soybean SM proteome (Clarke et al., unpublished). However, as this family also includes proteins that transport a range of different compounds including nitrate, auxin, glucosinolate, and peptides (see below), experimental characterization of the substrates will need to be performed before their role can be confirmed.

\section{TRANSPORT OF AMMONIA AND AMMONIUM}

The product of nitrogenase in bacteroids is ammonia, which is thought to diffuse out of the bacteroids into the acidic SS, where much of it is protonated to ammonium (Day et al., 2001a). Reuptake of ammonium into the bacteroids is prevented through repression of the bacteroid ammonium carrier during differentiation of rhizobia to their symbiotic state (Howitt et al., 1986). The SM is energized by an $\mathrm{H}^{+}$-ATPase that pumps $\mathrm{H}^{+}$ into the SS. Thus a concentration gradient is established that promotes the efflux of $\mathrm{NH}_{3} / \mathrm{NH}_{4}{ }^{+}$into the plant cytosol, where it is rapidly assimilated. In isolated symbiosomes, two avenues have been identified for the transport of $\mathrm{NH}_{3} / \mathrm{NH}_{4}{ }^{+}$across the $\mathrm{SM}$, a channel for facilitated diffusion of ammonia (Niemietz and Tyerman, 2000), and a voltage-gated monovalent cation channel that transports $\mathrm{NH}_{4}{ }^{+}$as well as potassium and sodium ions (Tyerman et al., 1995). The movement of $\mathrm{NH}_{4}{ }^{+}$is coordinated by the generation of a membrane potential across the SM by the $\mathrm{H}^{+}$-ATPase (Udvardi and Day, 1997, see below). The SM protein encoding the monovalent cation channel has not been identified, but nodulin 26 (NOD26), an aquaporin that transports water (Fortin et al., 1987; Dean et al., 1999; Niemietz and Tyerman, 2000; Hwang et al., 2010), is the likely candidate for passage of $\mathrm{NH}_{3}$. NOD26 was first identified as an integral membrane protein of the soybean SM (Fortin et al., 1987) and is a member of the major intrinsic protein/aquaporin (MIP/AQP) channel family (Wudick et al., 2009). It is estimated to constitute $10 \%$ of the protein content of the SM (Weaver et al., 1994; Rivers et al., 1997), is exclusively localized to the SM, and due to its prevalence is widely used as a marker for the membrane. NOD26 functions as a multifunctional aquaglyceroporin, with Xenopus oocyte studies showing it can facilitate the movement of glycerol and formamide (Rivers et al., 1997; Dean et al., 1999). Other studies have shown that it can also facilitate ammonia transport across the SM (Hwang et al., 2010) and it acts as a docking 
Table 1 | A summary of characterized transport processes of the legume symbiosome membrane indicating transported substrate, corresponding gene (if identified), and related publication(s).

\begin{tabular}{|c|c|c|c|c|}
\hline $\begin{array}{l}\text { Compound } \\
\text { transported }\end{array}$ & Biochemical characterization & $\begin{array}{l}\text { Gene encoding transporter } \\
\text { (evidence) }\end{array}$ & Reference & Direction \\
\hline Malate & Monovalent anion uptake assays & Not identified & Udvardi et al. (1988) & Import \\
\hline $\mathrm{Fe}^{3+}$ & Ferric chelate uptake assay & Not identified & LeVier et al. (1996) & Import \\
\hline Homocitrate & Inferred & Not identified & $\begin{array}{l}\text { Hoover et al. (1989), } \\
\text { Hakoyama et al. (2009) }\end{array}$ & Import \\
\hline IAA & IAA uptake assay into symbiosomes & Not identified & $\begin{array}{l}\text { Rosendahl and Jochimsen } \\
\text { (1995) }\end{array}$ & Import \\
\hline $\mathrm{SO}_{4}{ }^{2-}$ & $\begin{array}{l}\text { No biochemical activity measured on } \\
\text { symbiosomes }\end{array}$ & $\begin{array}{l}\text { SST1 (yeast } \\
\text { complementation) }\end{array}$ & Krusell et al. (2005) & Import? \\
\hline $\mathrm{H}^{+}$ & Assays for P-type $\mathrm{H}^{+}$-ATPase & $\begin{array}{l}H^{+} \text {-ATPase (sequence } \\
\text { homology, localization) }\end{array}$ & $\begin{array}{l}\text { Blumwald et al. (1985), } \\
\text { Udvardi et al. (1991), Fedorova } \\
\text { et al. (1999), Wienkoop and } \\
\text { Saalbach (2003), Clarke et al. } \\
\text { (unpublished) }\end{array}$ & Import \\
\hline $\begin{array}{l}\text { Branched chain } \\
\text { amino acids }\end{array}$ & Inferred & Not identified & Prell et al. (2009) & Import \\
\hline Amino acids? & & $\begin{array}{l}\text { GmAPC1 (sequence } \\
\text { homology, localization) }\end{array}$ & Clarke et al. (unpublished) & $?$ \\
\hline $\mathrm{K}^{+}, \mathrm{Na}^{+}, \mathrm{NH}_{4}^{+}$ & $\begin{array}{l}\text { Patch-clamp of voltage-gated monovalent } \\
\text { cation channel }\end{array}$ & Not identified & Tyerman et al. (1995) & Export \\
\hline
\end{tabular}

It should be noted that the orientation of the symbiosome is such that uptake into the symbiosome is equivalent to efflux across the plasma membrane. Uptake into heterologous expression systems such as yeast or oocyte represents the reverse direction; that is, efflux from a symbiosome. Hence demonstration of uptake into symbiosomes and yeast suggests that a transporter can operate bidirectionally.

station for cytosolic glutamine synthetase (Masalkar et al., 2010). This localization of glutamine synthetase would promote rapid assimilation of ammonia, thereby creating a strong sink for further export. The detection of both glutamine synthetase and NOD26 in the soybean SM proteome (Clarke et al., unpublished) provides further support for their suggested roles in ammonia release from the symbiosome (Hwang et al., 2010; Masalkar et al., 2010).

\section{ADDITIONAL TRANSPORT PROCESSES Energization of the SM}

The active pumping of $\mathrm{H}^{+}$ions by an $\mathrm{H}^{+}$-ATPase generates a proton gradient across the $\mathrm{SM}$, which is thought to drive many other transport processes (Blumwald et al., 1985; Udvardi and
Day, 1989; Andreev et al., 1999; Fedorova et al., 1999), as well as the conversion of ammonia to ammonium. P-type $\mathrm{H}^{+}$-ATPases are considered to have an important role in the development of the symbiotic association through their acidification of the SS, but they also energize the SM by establishing an electrochemical gradient across the membrane that is necessary for the secondary transport of other solutes (reviewed in Day et al., 2001a). Three related P-type $\mathrm{H}^{+}$-ATPases were identified in the soybean SM proteome (Clarke et al., unpublished), while a P-type $\mathrm{H}^{+}$-ATPase has been immunolocalized on the SM of soybean (Fedorova et al., 1999) and detected on the SM by proteomic analysis in L. japonicus and M. truncatula (Wienkoop and Saalbach, 2003; Catalano et al., 2004). Interestingly, the related V-type ATPases have also been identified proteomically on the SM in pea and $L$. 
japonicus (Saalbach et al., 2002; Wienkoop and Saalbach, 2003), but could not be detected by immunolocalization on the soybean SM (Fedorova et al., 1999). The absence of V-type ATPases in the soybean SM proteome, together with the results of Fedorova et al. (1999), suggest that soybeans may differ from other legumes in their SM ATPase requirements.

\section{Calcium transport}

It has been suggested that symbiosomes may behave as calcium stores in infected cells (Andreev et al., 1999). Calcium uptake is an active (ATP-driven) process and an ATP-driven $\mathrm{Ca}^{2+}$-pump has been characterized on the SM (Andreev et al., 1999; Krylova et al., 2012). Three $\mathrm{Ca}^{2+}$-ATPases were identified in the soybean SM proteome (Clarke et al., unpublished). Both the P-type $\mathrm{H}^{+}$-ATPases and these $\mathrm{Ca}^{2+}$-ATPases are expressed broadly across soybean tissues (Libault et al., 2010; Severin et al., 2010), suggesting recruitment to a new role and location as part of the symbiosis. Whether the symbiosome functions as a calcium store in vivo remains to be seen. The presence of a calcium-dependent protein kinase on the SM and its role in malate uptake into the symbiosome (Ouyang et al., 1991; Weaver et al., 1991) certainly shows the potential for calcium to be a key regulator of symbiosome function.

\section{Transport of other nitrogenous compounds}

Transport of nitrogenous compounds is of general interest in legumes, especially as nodule development is suppressed in the presence of nitrate (Streeter and Wong, 1988). In all plants, nitrogen plays an important regulatory role, which includes lateral root formation and, in the case of legumes, nodulation.

A nitrate transporter, GmN70, has been identified on the SM in soybean (Vincill et al., 2005). The L. japonicus ortholog, LjN70, also transports nitrate and both proteins are members of the major facilitator superfamily (MFS; Vincill et al., 2005). It is postulated that these transporters may aid in the regulation of ion and membrane potential through their transport of nitrate, which is known to regulate the symbiosis (Udvardi and Day, 1989). In isolated symbiosomes, rapid uptake of nitrate disperses the membrane potential (Udvardi et al., 1991).

As mentioned earlier, the NPF family has members whose expression is up-regulated during nodule development in a number of legumes. This large family has recently been divided into eight sub-families, NPF1-8 (Léran et al., 2014). Members of the NPF transport a range of nitrogen-based compounds (Williams and Millar, 2001). AtNPF6.3 (AtNRT1.1, CHL1), one of 53 proteins in the NPF of Arabidopsis, can transport nitrate (Tsay et al., 2007) and auxin (Krouk et al., 2010), as can the M. truncatula homolog MtNRT1.3 (Beeckman and Friml, 2010; MorereLe Paven et al., 2011). Uptake of the auxin, IAA, by isolated pea symbiosomes has been reported (Rosendahl and Jochimsen, 1995). NPF proteins with dual transport functions are implicated in nutrient sensing roles within the plant, in addition to high- and low-affinity nitrate uptake (Krouk et al., 2010). Other members of the NPF in Arabidopsis transport the defense compounds, glucosinolates, in seeds (Nour-Eldin et al., 2012), abscisic acid, peptides and dicarboxylates (see above).
Medicago truncatula MtNPF1.7 (previously called LATD/NIP), a nitrate transporter, is essential for the development and maintenance of lateral roots and release of rhizobia into the symbiosome (Bright et al., 2005; Harris and Dickstein, 2010; Yendrek et al., 2010). Complementation using Chl1 (NPF6.3) from Arabidopsis, a dual nitrate/auxin carrier, was able to rescue the latd/nip1 phenotype in lateral root development, but not the phenotype observed in nodules (Bagchi et al., 2012), suggesting it has other, unidentified functions. A member of the same sub-family, GmNPF1.2, is expressed specifically in nodules (Severin et al., 2010) and is present on the SM (Clarke et al., unpublished).

Other proteins homologous to the Arabidopsis NRT/PTR Family (NPF) have also been identified in the soybean SM proteome. One of these is closely related to Arabidopsis plasma membrane peptide transporters PTR1 and PTR5 (NPF8 sub-family), while others are in the sub-family of PTR3 (NPF5), also identified as a peptide transporter. The relevance of peptide transport on the $\mathrm{SM}$ is not clear. However, all these proteins contain the FING motif that is thought to be essential for peptide transport (Stacey et al., 2002). The genes encoding these proteins are expressed specifically in nodules in soybean (Severin et al., 2010) and proteins homologous to GmNPF5.24 and GmNPF5.25 were identified in the L. japonicus SM proteome (Wienkoop and Saalbach, 2003).

If NPF members transport peptides into the symbiosome they could be used to lift symbiotic auxotrophy for branched chain amino acids that was recently identified by Prell et al. (2009) in the pea: Rhizobium leguminasarum symbiosis (see below).

\section{Amino acid transport}

Isolated soybean symbiosomes are only weakly permeable to amino acids (Whitehead et al., 1998) so it is not likely that they are major contributors of carbon to bacteroids in soybean (Day et al., 2001b). However, recent studies have demonstrated that pea bacteroids are auxotrophs for branched chain amino acids (Prell et al., 2009). As the enclosed bacteroids are effectively organelles relying on the plant host to synthesize and provide branched chain amino acids, an SM amino acid transporter could act to facilitate this transport. A putative amino acid transporter (GmAPC1) with homology to the acid-polyamine organocation (APC) superfamily was identified in the soybean SM proteome (Clarke et al., unpublished). This family includes members that function as solute:cation symporters and solute:solute antiporters (Wong et al., 2012).

\section{Sulfur and molybdenum transport}

Sulfur is a component of the metalloclusters of nitrogenase, essential for the reduction of nitrogen, and must be actively transported across membranes (Krusell et al., 2005). LjSST1 was identified from a fix mutant in L. japonicus and complemented a yeast strain deficient in sulfate transport (Krusell et al., 2005). Peptides matching this sulfate transporter have been identified on the L. japonicus SM (Wienkoop and Saalbach, 2003) and two homologs found on the soybean SM (Clarke et al., unpublished). Krusell et al. (2005) reported that LjSST1 expression is essential for symbiotic nitrogen fixation; knockout mutants grow normally in non-symbiotic conditions but are unable to produce 
functioning nodules when inoculated with $M$. loti. Studies using ${ }^{35} \mathrm{SO}_{4}{ }^{-}$and isolated soybean symbiosomes failed to detect sulfate uptake (Day, unpublished data) and in this context, it should be noted that some members of the SST family, though not phylogenetically close to these candidates, can transport other metabolites in addition to sulfate, including molybdate (Tomatsu et al., 2007).

Molybdenum is an essential component of the nitrogenase enzyme. A high affinity ABC transport system encoded by Mod$A B C$ is involved in transport of molybdate in B. japonicum and required for efficient nitrogen fixation (Delgado et al., 2006) suggesting that there must be transport of molybdenum across the SM. Analysis of the soybean:B. japonicum symbiosis in modA or $\bmod B$ mutants suggested that in addition to ModABC, a combined molybdate and sulfate transport system was also present on the bacteroid membrane.

\section{Homocitrate transport}

Homocitrate is essential for nitrogen-fixation, as it is a component of the iron-molybdenum (FeMo) cofactor of nitrogenase complex (Hoover et al., 1989). Isolated rhizobia rely on the plant host to supply homocitrate, as in most cases they are not able to synthesis homocitrate endogenously (Zheng et al., 1997; Hakoyama et al., 2009). Homocitrate synthase in the plant is encoded by the FEN1 gene, and L. japonicus fen 1 mutants have reduced nitrogen fixation (Imaizumi-Anraku et al., 1997; Hakoyama et al., 2009) suggesting it is provided to bacteroids by the plant and that a transporter for homocitrate is likely to be present on the SM.

\section{Metal ion transport}

Iron is essential to the symbiosis as it is an integral component of proteins such as nitrogenase in the bacteroid and heme in the plant. The uptake of both ferrous and ferric iron into isolated symbiosomes has been demonstrated (Moreau et al., 1995, 1998; LeVier et al., 1996) and in soybean, GmDMT1 (Divalent Metal Transporter 1), a member of the NRAMP (Natural resistanceassociated macrophage protein) family of transporters, has been identified as a ferrous iron transporter on the SM and like many other NRAMP transporters has some specificity for other metal ions including zinc, magnesium and copper (Kaiser et al., 2003). However, it is not clear whether DMT1 would transport iron into the symbiosome. Given the orientation of the symbiosome, as deduced by its development from the plasma membrane, we would expect the inside of the symbiosome to correlate with the apoplast (outside the cell). Most members of the NRAMP family transport metals into the cytoplasm and GmDMT1 was characterized by its ability to transport iron into a yeast cell. By analogy, in situ, GmDMT1 would transport iron out of the symbiosome, suggesting a role in regulating iron availability in the cytoplasm that is similar to Arabidopsis NRAMP3 and 4 (Lanquar et al., 2005) by remobilizing iron stored in the symbiosome (Udvardi and Day, 1997). However, it is possible that this transporter could be bidirectional (Kaiser et al., 2003).

Lotus japonicus SEN1 is a member of the Vacuolar Iron transporter (VIT1) family and is expressed specifically in nodule infected cells (Hakoyama et al., 2012). Arabidopsis VIT1 transports ferrous iron into the vacuole (Kim et al., 2006), analogous to import into the symbiosome. Sen1 is essential for nitrogen fixation in L. japonicus suggesting it may have a role as an iron importer on the SM (Hakoyama et al., 2012). However, to date the substrate transported by SEN1 and its localization in infected cells has not been determined.

A zinc transporter, ZIP1 (Zinc regulated transporter/Iron regulated transporter-like Protein 1), has also been localized to the symbiosome and the antibodies raised against ZIP1 were able to inhibit uptake of zinc by isolated symbiosomes (Moreau et al., 2002). There has been little work on copper and manganese transport across the SM, though manganese transporters have been identified on the bacteroid membrane of a number of rhizobia and some of these result in fix ${ }^{-}$phenotypes (reviewed in Udvardi and Poole, 2013).

Recently, proteins homologous to the PLAC8 superfamily, which may include metal ion transporters, were identified in the SM proteome (Clarke et al., unpublished). A subset of the PLAC8 family, known as plant cadmium resistance (PCR) proteins in plants, are a large conserved family found in fungi, algae, higher plants and animals (Song et al., 2011). They are of particular interest on the SM as two members of this family in Arabidopsis have been reported to play a role in the transport of heavy metals (Song et al., 2004, 2010). AtPCR1 and AtPCR2 are reported to extrude divalent cations such as cadmium and zinc from Arabidopsis root cells (Song et al., 2004, 2010). This would translate to an import of metal into the symbiosome and the presence of homologous proteins on the SM suggests a role in maintaining adequate nutrition for the isolated bacteroids through import of a variety of metal cations. The identification of this family as transport proteins, however, is controversial as another member of the same sub-family, FW2.2, has been shown to mediate fruit weight in tomato (Frary et al., 2000) and a role for GmFWL1 (FW2.2-like 1) in controlling nuclear size and chromatin condensation has been suggested (Libault and Stacey, 2010). However, these effects could be indirectly related to metal ion transport and compartmentalization. Clearly more work needs to done in this area to elucidate the precise role of these membrane proteins.

\section{CONCLUSION}

The SM is the critical interface between the symbiotic partners and we still have a lot to learn about it. It is likely that a number of as yet unidentified metabolites are exchanged between the symbiotic partners in legumes. Processes that require transport of metabolites across the SM can be predicted and many putative transporters and novel integral membrane proteins have been identified on the SM through proteomic (Wienkoop and Saalbach, 2003; Catalano et al., 2004; Clarke et al., unpublished) and other approaches. Add to this the number of putative transporters with nodule specific or enhanced expression identified by studying legume transcriptomes (Benedito et al., 2010; Libault et al., 2010; Severin et al., 2010; Verdier et al., 2013) and it is clear that there is a long way to go to understand the associated metabolism and the role of transporters both on the SM and other cellular membranes in the nodule. With a more complete 
picture of the proteins on the $\mathrm{SM}$, reverse genetic approaches can be implemented to demonstrate the phenotypes associated with disrupting particular proteins. By combining this with biochemical and biophysical assays of transport, which can now be revisited based on new genetic and molecular data available, we should be able to extend our knowledge of the transport processes required for an efficient symbiosis and perhaps identify means by which we could enhance the process and so the benefits of BNF.

\section{AUTHOR CONTRIBUTIONS}

Victoria C. Clarke and Penelope M. C. Smith wrote the manuscript, Victoria C. Clarke, Patrick C. Loughlin, David A. Day, and Penelope M. C. Smith edited the manuscript.

\section{REFERENCES}

Andreev, I. M., Dubrovo, P. N., Krylova, V. V., and Izmailov, S. F. (1999). Functional identification of ATP-driven $\mathrm{Ca}^{2+}$ pump in the peribacteroid membrane of broad bean root nodules. FEBS Lett. 447, 49-52. doi: 10.1016/S00145793(99)00262-8

Bagchi, R., Salehin, M., Adeyemo, O. S., Salazar, C., Shulaev, V., Sherrier, D. J., et al. (2012). Functional assessment of the Medicago truncatula NIP/LATD protein demonstrates that it is a high-affinity nitrate transporter. Plant Physiol. 160, 906-916. doi: 10.1104/pp.112.196444

Beatty, P. H., and Good, A. G. (2011). Plant science. Future prospects for cereals that fix nitrogen. Science 333, 416-417. doi: 10.1126/science.1209467

Beeckman, T., and Friml, J. (2010). Nitrate contra auxin: nutrient sensing by roots. Dev. Cell 18, 877-878. doi: 10.1016/j.devcel.2010.05.020

Benedito, V. A., Li, H., Dai, X., Wandrey, M., He, J., Kaundal, R., et al. (2010). Genomic inventory and transcriptional analysis of Medicago truncatula transporters. Plant Physiol. 152, 1716-1730. doi: 10.1104/pp.109.148684

Benedito, V. A., Torres-Jerez, I., Murray, J. D., Andriankaja, A., Allen, S., Kakar, K., et al. (2008). A gene expression atlas of the model legume Medicago truncatula. Plant J. 55, 504-513. doi: 10.1111/j.1365-313X.2008.03519.x

Blumwald, E., Fortin, M. G., Rea, P. A., Verma, D. P. S., and Poole, R. J. (1985). Presence of host plasma membrane type $\mathrm{H}^{+}$-ATPase in the membrane envelope enclosing the bacteroids in soybean root nodules. Plant Physiol. 78, 655-672. doi: 10.1104/pp.78.4.665

Bright, L. J., Liang, Y., Mitchell, D. M., and Harris, J. M. (2005). The LATD gene of Medicago truncatula is required for both nodule and root development. Mol. Plant Microbe Interact. 18, 521-532. doi: 10.1094/MPMI-18-0521

Catalano, C. M., Lane, W. S., and Sherrier, D. J. (2004). Biochemical characterization of symbiosome membrane proteins from Medicago truncatula root nodules. Electrophoresis 25, 519-531. doi: 10.1002/elps.200305711

Colebatch, G., Desbrosses, G., Ott, T., Krusell, L., Montanari, O., Kloska, S., et al. (2004). Global changes in transcription orchestrate metabolic differentiation during symbiotic nitrogen fixation in Lotus japonicus. Plant J. 39, 487-512. doi: 10.1111/j.1365-313X.2004.02150.x

Coque, L., Neogi, P., Pislariu, C., Wilson, K. A., Catalano, C., Avadhani, M., et al. (2008). Transcription of ENOD8 in Medicago truncatula nodules directs ENOD8 esterase to developing and mature symbiosomes. Mol. Plant Microbe Interact. 21, 404-410. doi: 10.1094/MPMI-21-4-0404

Day, D. A., Kaiser, B. N., Thomson, R., Udvardi, M. K., Moreau, S., and Puppo, A. (2001a). Nutrient transport across symbiotic membranes from legume nodules. Aust. J. Plant Physiol. 28, 667-674. doi: 10.1071/PP01028

Day, D. A., Poole, P. S., Tyerman, S. D., and Rosendahl, L. (2001b). Ammonia and amino acid transport across symbiotic membranes in nitrogen-fixing legume nodules. Cell. Mol. Life Sci. 58, 61-71. doi: 10.1007/PL00000778

Day, D. A., Whitehead, L. F., Hendriks, J. H. M., and Tyerman, S. D. (1995). "Nitrogen and carbon exchange across symbiotic membranes from soybean nodules," in Nitrogen Fixation: Fundamentals and Applications, eds I. A. Tikhonovich, N. A. Provorov, V. I. Romanov, and W. E. Newton (Dordrecht: Kluwer Academic Publishers), 557-564.

Dean, R. M., Rivers, R. L., Zeidel, M. L., and Roberts, D. M. (1999). Purification and functional reconstitution of soybean nodulin 26. An aquaporin with water and glycerol transport properties. Biochemistry 38, 347-353. doi: 10.1021/bi982110c
Delgado, M. J., Tresierra-Ayala, A., Talbi, C., and Bedmar, E. J. (2006). Functional characterization of the Bradyrhizobium japonicum modA and $\operatorname{modB}$ genes involved in molybdenum transport. Microbiology 152, 199-207. doi: 10.1099/mic. $0.28347-0$

Esseling, J. J., Lhuissier, F. G. P., and Emons, A. M. C. (2003). Nod factor-induced root hair curling: continuous polar growth towards the point of nod factor application. Plant Physiol. 132, 1982-1988. doi: 10.1104/pp.103.021634

Fedorova, E., Thomson, R., Whitehead, L. F., Maudoux, O., Udvardi, M. K., and Day, D. A. (1999). Localization of $\mathrm{H}^{+}$-ATPases in soybean root nodules. Planta 209, 25-32. doi: 10.1007/s004250050603

Fortin, M. G., Morrison, N. A., and Verma, D. P. S. (1987). Nodulin-26, a peribacteroid membrane nodulin is expressed independently of the development of the peribacteroid compartment. Nucleic Acids Res. 15, 813-824. doi: $10.1093 / \mathrm{nar} / 15.2 .813$

Frary, A., Nesbitt, T. C., Grandillo, S., Knaap, E., Cong, B., Liu, J., et al. (2000). fw2.2: a quantitative trait locus key to the evolution of tomato fruit size. Science 289, 85-88. doi: 10.1126/science.289.5476.85

Hakoyama, T., Niimi, K., Watanabe, H., Tabata, R., Matsubara, J., Sato, S., et al. (2009). Host plant genome overcomes the lack of a bacterial gene for symbiotic nitrogen fixation. Nature 462, 514-517. doi: 10.1038/nature08594

Hakoyama, T., Niimi, K., Yamamoto, T., Isobe, S., Sato, S., Nakamura, Y., et al. (2012). The integral membrane protein SEN1 is required for symbiotic nitrogen fixation in Lotus japonicus nodules. Plant Cell Physiol. 53, 225-236. doi: $10.1093 / \mathrm{pcp} / \mathrm{pcr} 167$

Halbleib, C. M., and Ludden, P. W. (2000). Regulation of biological nitrogen fixation. J. Nutr. 130, 1081-1084.

Harris, J. M., and Dickstein, R. (2010). Control of root architecture and nodulation by the LATD/NIP transporter. Plant Signal. Behav. 5, 1365-1369. doi: $10.4161 /$ psb.5.11.13165

Herridge, D. F., Peoples, M. B., and Boddy, R. M. (2008). Global inputs of biological nitrogen fixation in agricultural systems. Plant Soil 311, 1-18. doi: 10.1007/s11104-008-9668-3

Hirsch, A. M. (1992). Developmental biology of legume nodulation. New Phytol. 122, 211-237. doi: 10.1111/j.1469-8137.1992.tb04227.x

Hohnjec, N., Lenz, F., Fehlberg, V., Vieweg, M. F., Baler, M. C., Hause, B., et al. (2009). The signal peptide of the Medicago truncatula modular nodulin MtNOD25 operates as an address label for the specific targeting of proteins to nitrogen-fixing symbiosomes. Mol. Plant Microbe Interact. 22, 63-72. doi: 10.1094/MPMI-22-1-0063

Hoover, T. R., Imperial, J., Ludden, P. W., and Shah, V. K. (1989). Homocitrate is a component of the iron-molybdenum cofactor of nitrogenase. Biochemistry 28, 2768-2771. doi: 10.1021/bi00433a004

Howitt, S. M., Udvardi, M. K., Day, D. A., and Gresshoff, P. M. (1986). Ammonia transport in free-living and symbiotic Rhizobium sp. ANU289. J. Gen. Microbiol. 132, 257-261. doi: 10.1099/00221287-132-2-257

Hwang, J. H., Ellingson, S. R., and Roberts, D. M. (2010). Ammonia permeability of the soybean nodulin 26 channel. FEBS Lett. 584, 4339-4343. doi: 10.1016/j.febslet.2010.09.033

Imaizumi-Anraku, H., Kawaguchi, M., Koiwa, H., Akao, S., and Syono, K. (1997). Two ineffective-nodulating mutants of Lotus japonicus-different phenotypes caused by the blockage of endocytotic bacterial release and nodule maturation. Plant Cell Physiol. 38, 871-881. doi: 10.1093/oxfordjournals.pcp.a029246

Ivanov, S., Fedorova, E. E., Limpens, E., De Mita, S., Genre, A., Bonfante, P., et al. (2012). Rhizobium-legume symbiosis shares an exocytotic pathway required for arbuscule formation. Proc. Natl. Acad. Sci. U.S.A. 109, 8316-8321. doi: 10.1073/pnas. 1200407109

Jeong, J., Suh, S., Guan, C., Tsay, Y. F., Moran, N., Oh, C. J., et al. (2004). A nodule-specific dicarboxylate transporter from alder is a member of the peptide transporter family. Plant Physiol. 134, 969-978. doi: 10.1104/pp.103.032102

Kaiser, B. N., Moreau, S., Castelli, J., Thomson, R., Lambert, A., Bogliolo, S., et al. (2003). The soybean NRAMP homologue, GmDMT1, is a symbiotic divalent metal transporter capable of ferrous iron transport. Plant J. 35, 295-304. doi: 10.1046/j.1365-313X.2003.01802.x

Kim, S. A., Punshon, T., Lanzirotti, A., Li, L., Alonso, J. M., Ecker, J. R., et al. (2006). Localization of iron in Arabidopsis seed requires the vacuolar membrane transporter VIT1. Science 314, 1295-1298. doi: 10.1126/science. 1132563

Krouk, G., Lacombe, B., Bielach, A., Perrine-Walker, F., Malinska, K., Mounier, E., et al. (2010). Nitrate-regulated auxin transport by NRT1.1 defines a 
mechanism for nutrient sensing in plants. Dev. Cell 18, 927-937. doi: 10.1016/j.devcel.2010.05.008

Krusell, L., Krause, K., Ott, T., Desbrosses, G., Krämer, U., Sato, S., et al. (2005). The sulfate transporter SST1 is crucial for symbiotic nitrogen fixation in Lotus japonicus root nodules. Plant Cell 17, 1625-1636. doi: 10.1105/tpc.104.030106

Krylova, V., Andreev, I. M., Zartdinova, R., and Izmailov, S. F. (2012). Biochemical characteristics of the $\mathrm{Ca}^{2+}$ pumping ATPase in the peribacteroid membrane from broad bean root nodules. Protoplasma 250, 531-538. doi: 10.1007/s00709012-0436-0

Lanquar, V., Lelievre, F., Bolte, S., Hames, C., Alcon, C., Neumann, D., et al. (2005). Mobilization of vacuolar iron by AtNRAMP3 and AtNRAMP4 is essential for seed germination on low iron. EMBO J. 24, 4041-4051. doi: 10.1038/s.emboj.7600864

Léran, S., Varala, K., Boyer, J. C., Chiurazzi, M., Crawford, N., Daniel-Vedele, F., et al. (2014). A unified nomenclature of NITRATE TRANSPORTER 1/PEPTIDE TRANSPORTER family members in plants. Trends Plant Sci. 19, 5-9. doi: 10.1016/j.tplants.2013.08.008

LeVier, K., Day, D. A., and Guerinot, M. L. (1996). Iron uptake by symbiosomes from soybean root nodules. Plant Physiol. 111, 893-900.

Libault, M., Farmer, A., Brechenmacher, L., Drnevich, J., Langley, R. J., Bilgin, D. D., et al. (2010). Complete transcriptome of the soybean root hair cell, a singlecell model, and its alteration in response to Bradyrhizobium japonicum infection. Plant Physiol. 152, 541-552. doi: 10.1104/pp.109.148379

Libault, M., and Stacey, G. (2010). Evolution of FW2.2-like (FWL) and PLAC8 genes in eukaryotes. Plant Signal. Behav. 5, 1226-1228. doi: 10.4161/ psb.5.10.12808

Limpens, E., Lvanov, S., Van Esse, W., Voets, G., Fedorova, E., and Bisseling, T. (2009). Medicago N2-Fixing symbiosomes acquire the endocytic identity marker Rab7 but delay the acquisition of vacuolar identity. Plant Cell 21, 28112828. doi: $10.1105 /$ tpc. 108.064410

Liu, J., Miller, S. S., Graham, M., Bucciarelli, B., Catalano, C. M., Sherrier, D. J., et al. (2006). Recruitment of novel calcium-binding proteins for root nodule symbiosis in Medicago truncatula. Plant Physiol. 141, 167-177. doi: 10.1104/pp.106.076711

Lodwig, E., and Poole, P. S. (2003). Metabolism of Rhizobium bacteroids. Crit. Rev. Plant Sci. 22, 37-78. doi: 10.1080/713610850

Masalkar, P., Wallace, I. S., Hwang, J. H., and Roberts, D. M. (2010). Interaction of cytosolic glutamine synthetase of soybean root nodules with the C-terminal domain of the symbiosome membrane nodulin 26 aquaglyceroporin. J. Biol. Chem. 285, 23880-23888. doi: 10.1074/jbc.M110.135657

Meckfessel, M. H., Blancaflor, E. B., Plunkett, M., Dong, Q., and Dickstein, R. (2012). Multiple domains in MtENOD8 protein including the signal peptide target it to the symbiosome. Plant Physiol. 159, 299-310. doi: 10.1104/pp.111.191403

Moreau, S., Day, D. A., and Puppo, A. (1998). Ferrous iron is transported across the peribacteroid membrane of soybean nodules. Planta 207, 83-87. doi: $10.1007 / \mathrm{s} 004250050458$

Moreau, S., Meyer, J. M., and Puppo, A. (1995). Uptake of iron by symbiosomes and bacteroids from soybean nodules. FEBS Lett. 361, 225-228. doi: 10.1016/00145793(95)00155-3

Moreau, S., Thompson, R. M., Kaiser, B. N., Trevaskis, B., Guerinot, M. L., Udvardi, M. K., et al. (2002). GmZIP1 encodes a symbiosome-specific zinc transporter in soybean. J. Biol. Chem. 277, 4738-4746. doi: 10.1074/jbc.M106754200

Morere-Le Paven, M. C., Viau, L., Hamon, A., Vandecasteele, C., Pellizzaro, A., Bourdin, C., et al. (2011). Characterization of a dual-affinity nitrate transporter MtNRT1.3 in the model legume Medicago truncatula. J. Exp. Biol. 62, 55955605. doi: $10.1093 /$ jxb/err243

Niemietz, C. M., and Tyerman, S. D. (2000). Channel-mediated permeation of ammonia gas through the peribacteroid membrane of soybean nodules. FEBS Lett. 465, 110-114. doi: 10.1016/S0014-5793(99)01729-9

Nour-Eldin, H. H., Andersen, T. G., Burow, M., Madsen, S. R., Jorgensen, M. E., Olsen, C. E., et al. (2012). NRT/PTR transporters are essential for translocation of glucosinolate defence compounds to seeds. Nature 488, 531-534. doi: 10.1038/nature11285

Oldroyd, G. E., and Downie, J. A. (2004). Calcium, kinases and nodulation signalling in legumes. Nat. Rev. Mol. Cell Biol. 5, 566-576. doi: 10.1038/nrm1424

Oldroyd, G. E. D., Murray, J. D., Poole, P. S., and Downie, J. A. (2011). The rules of engagement in the legume-rhizobial symbiosis. Annu. Rev. Genet. 45, 119-44. doi: 10.1146/annurev-genet-110410-132549
Ouyang, L. J., Whelan, J., Weaver, C. D., Roberts, D. M., and Day, D. A. (1991). Protein phosphorylation stimulates the rate of malate uptake across the peribacteroid membrane of soybean nodules. FEBS Lett. 293, 188-190. doi: 10.1016/0014-5793(91)81183-9

Prell, J., White, J. P., Bourdes, A., Bunnewell, S., Bongaerts, R. J., and Poole, P. S. (2009). Legumes regulate Rhizobium bacteroid development and persistence by the supply of branched-chain amino acids. Proc. Natl. Acad. Sci. U.S.A. 106, 12477-12482. doi: 10.1073/pnas.0903653106

Rivers, R. L., Dean, R. M., Chandy, G., Hall, J. E., Roberts, D. M., and Zeidel, M. L. (1997). Functional analysis of nodulin 26, an aquaporin in soybean root nodule symbiosomes. J. Biol. Chem. 272, 16256-16261. doi: 10.1074/jbc.272.26. 16256

Rosendahl, L., and Jochimsen, B. U. (1995). In vitro indole-3-acetic acid uptake in symbiosomes from soybean (Glycine max L.) root nodules. Symbiosis 19, 99-110.

Roth, E., Jeon, K., and Stacey, G. (1988). "Homology in endosymbiotic systems: the term 'symbiosome," in Molecular Genetics of Plant Microbe Interactions, eds R. Palacios and D. P. S. Verma (St Paul, MN: American Phytopathological Society Press), 220-225.

Roth, L. E., and Stacey, G. (1989). Cytoplasmic membrane systems involved in bacterium release into soybean nodule cells as studied with two Bradyrhizobium japonicum mutant strains. Eur. J. Cell Biol. 49, 24-32.

Saalbach, G., Erik, P., and Wienkoop, S. (2002). Characterisation by proteomics of peribacteroid space and peribacteroid membrane preparations from pea (Pisum sativum) symbiosomes. Proteomics 2, 325-337. doi: 10.1002/16159861(200203)2:3<325::AID-PROT325>3.0.CO;2-W

Schmutz, J., Cannon, S. B., Schlueter, J., Ma, J., Mitros, T., Nelson, W., et al. (2010). Genome sequence of the palaeopolyploid soybean. Nature 463, 178-183. doi: 10.1038/nature 08670

Severin, A. J., Woody, J. L., Bolon, Y. T., Joseph, B., Diers, B. W., Farmer, A. D., et al. (2010). RNA-seq atlas of glycine max: a guide to the soybean transcriptome. BMC Plant Biol. 10:160. doi: 10.1186/1471-2229-10-160

Song, W. Y., Choi, K. S., Kim Do, Y., Geisler, M., Park, J., Vincenzetti, V., et al. (2010). Arabidopsis PCR2 is a zinc exporter involved in both zinc extrusion and long-distance zinc transport. Plant Cell 22, 2237-2252. doi: 10.1105/tpc.109.070185

Song, W. Y., Hortensteiner, S., Tomioka, R., Lee, Y., and Martinoia, E. (2011). Common functions or only phylogenetically related? The large family of PLAC8 motif-containing/PCR genes. Mol. Cells 31, 1-7. doi: 10.1007/s10059-0110024-8

Song, W. Y., Martinoia, E., Lee, J., Kim, D., Kim, D. Y., Vogt, E., et al. (2004). A novel family of cys-rich membrane proteins mediates cadmium resistance in Arabidopsis. Plant Physiol. 135, 1027-1039. doi: 10.1104/pp.103.037739

Stacey, G., Koh, S., Granger, C., and Becker, J. M. (2002). Peptide transport in plants. Trends Plant Sci. 7, 257-263. doi: 10.1016/S1360-1385(02)02249-5

Streeter, J., and Wong, P. P. (1988). Inhibition of legume nodule formation and N2 fixation by nitrate. Crit. Rev. Plant Sci. 7, 1-23. doi: 10.1080/07352688809382257

Timmers, A. C., Auriac, M. C., and Truchet, G. (1999). Refined analysis of early symbiotic steps of the Rhizobium-Medicago interaction in relationship with microtubular cytoskeleton rearrangements. Development 126, 3617-3628.

Tomatsu, H., Takano, J., Takahashi, H., Watanabe-Takahashi, A., Shibagaki, N., and Fujiwara, T. (2007). An Arabidopsis thaliana high-affinity molybdate transporter required for efficient uptake of molybdate from soil. Proc. Natl. Acad. Sci. U.S.A. 104, 18807-18812. doi: 10.1073/pnas.0706373104

Tsay, Y. F., Chiu, C. C., Tsai, C. B., Ho, C. H., and Hsu, P. K. (2007). Nitrate transporters and peptide transporters. FEBS Lett. 581, 2290-2300. doi: 10.1016/j.febslet.2007.04.047

Tyerman, S. D., Whitehead, L. F., and Day, D. A. (1995). A channel-like transporter for $\mathrm{NH}_{4}{ }^{+}$on the symbiotic interface of N2-fixing plants. Nature 378, 629-632. doi: $10.1038 / 378629 \mathrm{a} 0$

Udvardi, M., and Poole, P. S. (2013). Transport and metabolism in legume-rhizobia symbioses. Annu. Rev. Plant Biol. 64, 781-805. doi: 10.1146/annurev-arplant050312-120235

Udvardi, M. K., and Day, D. A. (1989). Electrogenic ATPase activity on the peribacteroid membrane of soybean (Glycine max L.) root nodules. Plant Physiol. 90, 982-987. doi: 10.1104/pp.90.3.982

Udvardi, M. K., and Day, D. A. (1997). Metabolite transport across symbiotic membranes of legume nodules. Annu. Rev. Plant Physiol. Plant Mol. Biol. 48, 493-523. doi: 10.1146/annurev.arplant.48.1.493 
Udvardi, M. K., Lister, D. L., and Day, D. A. (1991). ATPase activity and anion transport across the peribacteroid membrane of isolated soybean symbiosomes. Arch. Microbiol. 156, 362-366. doi: 10.1007/BF00248711

Udvardi, M. K., Price, G. D., Gresshoff, P. M., and Day, D. A. (1988). A dicarboxylate transporter on the peribacteroid membrane of soybean nodules. FEBS Lett. 231, 36-40. doi: 10.1016/0014-5793(88)80697-5

Vance, C. P. (2001). Symbiotic nitrogen fixation and phosphorus acquisition. Plant nutrition in a world of declining renewable resources. Plant Physiol. 127, 390 397. doi: 10.1104/pp.010331

Verdier, J., Torres-Jerez, I., Wang, M., Andriankaja, A., Allen, S. N., He, J., et al. (2013). Establishment of the Lotus japonicus Gene Expression Atlas (LjGEA) and its use to explore legume seed maturation. Plant J. 74, 351-362. doi: 10.1111/tpj.12119

Vincill, E. D., Szczyglowski, K., and Roberts, D. M. (2005). GmN70 and LjN70. Anion transporters of the symbiosome membrane of nodules with a transport preference for nitrate. Plant Physiol. 137, 1435-1444. doi: 10.1104/pp.104.051953

Weaver, C. D., Crombie, B., Stacey, G., and Roberts, D. M. (1991). Calciumdependent phosphorylation of symbiosome membrane proteins from nitrogenfixing soybean nodules : evidence for phosphorylation of nodulin-26. Plant Physiol. 95, 222-227. doi: 10.1104/pp.95.1.222

Weaver, C. D., Shomer, N. H., Louis, C. F., and Roberts, D. M. (1994). Nodulin 26 , a nodule-specific symbiosome membrane protein from soybean, is an ion channel. J. Biol. Chem. 269, 17858-17862.

Whitehead, L. F., and Day, D. A. (1997). The peribacteroid membrane. Physiol. Plant. 100, 30-44. doi: 10.1111/j.1399-3054.1997.tb03452.x

Whitehead, L. F., Young, S., and Day, D. A. (1998). Aspartate and alanine movement across symbiotic membranes of soybean nodules. Soil Biol. Biochem. 30, 1583-1589. doi: 10.1016/S0038-0717(97) 00229-0

Wienkoop, S., and Saalbach, G. (2003). Proteome analysis. Novel proteins identified at the peribacteroid membrane from Lotus japonicus root nodules. Plant Physiol. 131, 1080-1090. doi: 10.1104/pp.102.015362
Williams, L. E., and Millar, A. J. (2001). Transporters responsible for the uptake and partitioning of nitrogenous solutes. Annu. Rev. Plant Physiol. Plant Mol. Biol. 52, 659-688. doi: 10.1146/annurev.arplant.52.1.659

Wong, F. H., Chen, J. S., Reddy, V., Day, J. L., Shlykov, M. A., Wakabayashi, S. T., et al. (2012). The amino acid-polyamine-organocation superfamily. J. Mol. Microbiol. Biotechnol. 22, 105-113. doi: 10.1159/000338542

Wudick, M. M., Luu, D. T., and Maurel, C. (2009). A look inside: localization patterns and functions of intracellular plant aquaporins. New Phytol. 184, 289302. doi: 10.1111/j.1469-8137.2009.02985.x

Yendrek, C. R., Lee, Y. C., Morris, V., Liang, Y., Pislariu, C. I., Burkart, G., et al. (2010). A putative transporter is essential for integrating nutrient and hormone signaling with lateral root growth and nodule development in Medicago truncatula. Plant J. 62, 100-112. doi: 10.1111/j.1365-313X.2010.04134.x

Zheng, L., White, R. H., and Dean, D. R. (1997). Purification of the Azotobacter vinelandii nifV-encoded homocitrate synthase. J. Bacteriol. 179, 5963-5966.

Conflict of Interest Statement: The authors declare that the research was conducted in the absence of any commercial or financial relationships that could be construed as a potential conflict of interest.

Received: 03 October 2014; paper pending published: 31 October 2014; accepted: 24 November 2014; published online: 15 December 2014.

Citation: Clarke VC, Loughlin PC, Day DA and Smith PMC (2014) Transport processes of the legume symbiosome membrane. Front. Plant Sci. 5:699. doi: $10.3389 / \mathrm{fpls} .2014 .00699$

This article was submitted to Plant Traffic and Transport, a section of the journal Frontiers in Plant Science.

Copyright (c) 2014 Clarke, Loughlin, Day and Smith. This is an open-access article distributed under the terms of the Creative Commons Attribution License (CC BY). The use, distribution or reproduction in other forums is permitted, provided the original author(s) or licensor are credited and that the original publication in this journal is cited, in accordance with accepted academic practice. No use, distribution or reproduction is permitted which does not comply with these terms. 